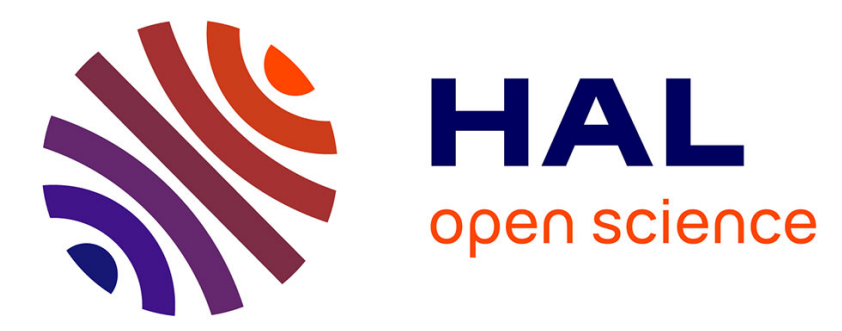

\title{
UCANS-8 in Paris Eighth International Meeting of the Union for Compact Accelerator-Driven Neutron Sources
}

\author{
Christiane Alba-Simionesco, Alain Menelle, Frédéric Ott
}

\section{To cite this version:}

Christiane Alba-Simionesco, Alain Menelle, Frédéric Ott. UCANS-8 in Paris Eighth International Meeting of the Union for Compact Accelerator-Driven Neutron Sources. Neutron News, 2019, 10.1080/10448632.2019.1695503 . hal-02407455

\section{HAL Id: hal-02407455 \\ https://hal.science/hal-02407455}

Submitted on 3 Dec 2020

HAL is a multi-disciplinary open access archive for the deposit and dissemination of scientific research documents, whether they are published or not. The documents may come from teaching and research institutions in France or abroad, or from public or private research centers.
L'archive ouverte pluridisciplinaire HAL, est destinée au dépôt et à la diffusion de documents scientifiques de niveau recherche, publiés ou non, émanant des établissements d'enseignement et de recherche français ou étrangers, des laboratoires publics ou privés. 


\section{UCANS-8 in Paris Eighth International Meeting of the Union for Compact Accelerator-Driven Neutron Sources}

C. Alba-Simionesco

A. Menelle, F. OtT

Laboratoire Léon Brillouin

CEA/CNRS, Univ. Paris Saclay

\section{QUERY SHEET}

This page lists questions we have about your paper. The numbers displayed at the left can be found in the text of the paper for reference. You will find these queries displayed as small red boxes within the text or in the margin areas.

In addition, please review your paper as a whole for correctness, paying close attention to special characters and math symbols.

$<\mathrm{AQ} 1>$ Please confirm author names and affiliations are correct $</ \mathrm{AQ}>$

$<\mathrm{AQ} 2>$ Please confirm if Figure 2 is captioned correctly $</ \mathrm{AQ}>$

$<$ AQ3 $>$ Please add an in-text call-out of Figure 2</AQ $>$ 


\section{UCANS-8 in Paris Eighth International Meeting of the Union for Compact Accelerator-Driven Neutron Sources}

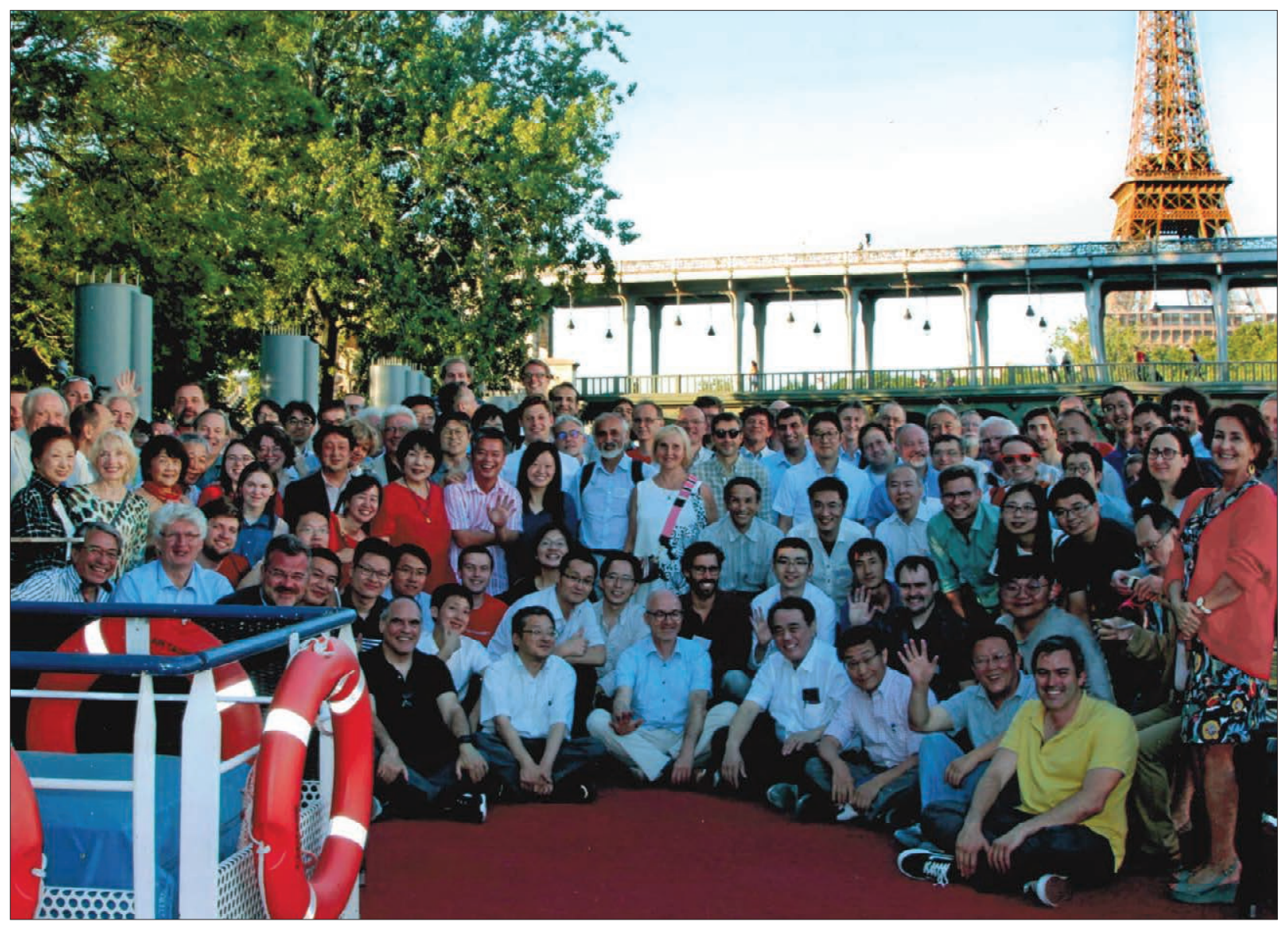

Figure 1. The participants enjoying a pleasant summer evening in Paris.

$\mathbf{T}$ he $8^{\text {th }}$ international meeting of the Union for Compact Accelerator-Driven Neutron Sources (UCANS-8) was held in Paris, July $8-11,2019$. Over 140 participants from more than a dozen countries from various continents attended the event (Figure 1). The conference was opened by John Carpenter whose speech retraced the motivations for the creation of the UCANS.
The field of neutron science has been supported over several decades by dozens of small- and mediumsize reactors built at laboratories and universities. These reactors have been supporting scientific activities in a very broad range of topics. However, an important number of them have been closed or will be closing in the future without any replacements planned. Considering the re- sults of centers such as LENS (USA) or Bariloche (Argentina), it was proposed in 2010 that regular meetings should be organized to share information on Compact Accelerator-based Neutron sources (CANS). Since then, a number of new projects have emerged across the world and several CANS have been built.

It was shown during the conference that CANS are a viable ap- 


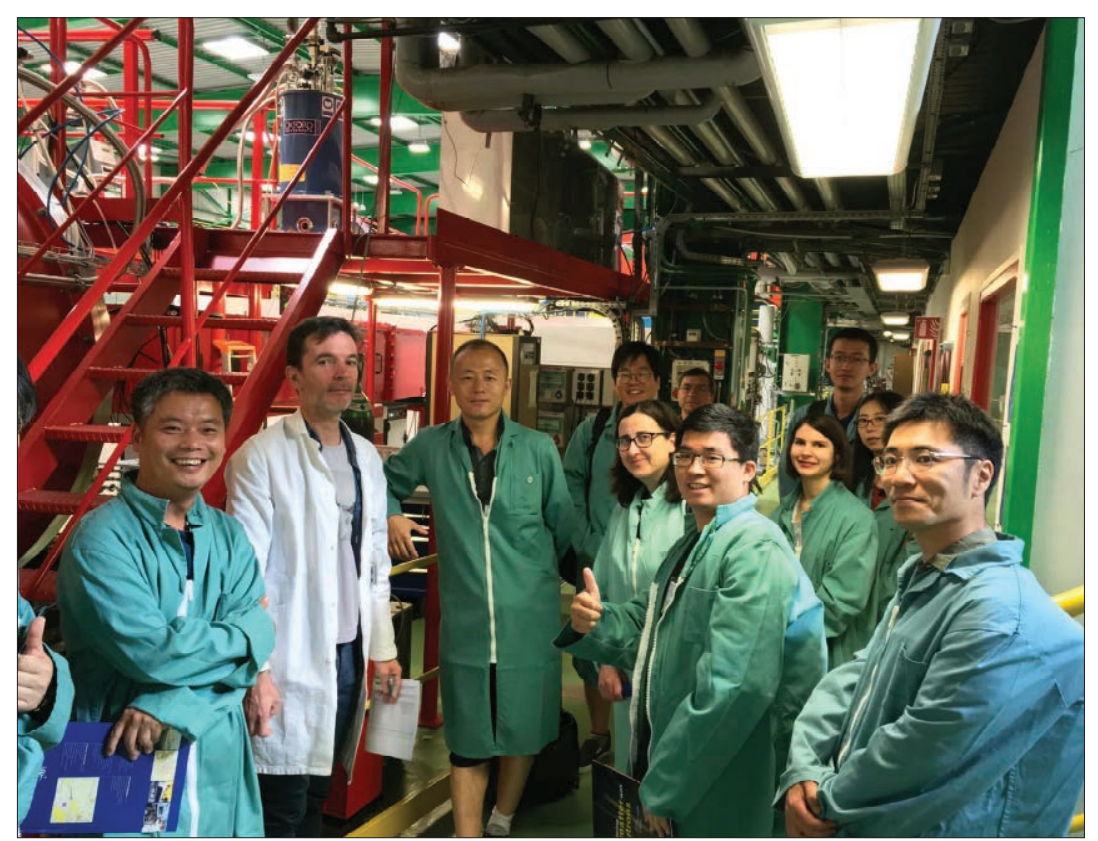

Figure 2. The participants of the conference had the opportunity to visit the neutron scattering instruments of the Laboratoire Léon Brillouin at the Orphée reactor (above) and the IPHI - Neutrons accelerator setup (below) in Saclay. $\mathbf{A Q 2}$ AQ3

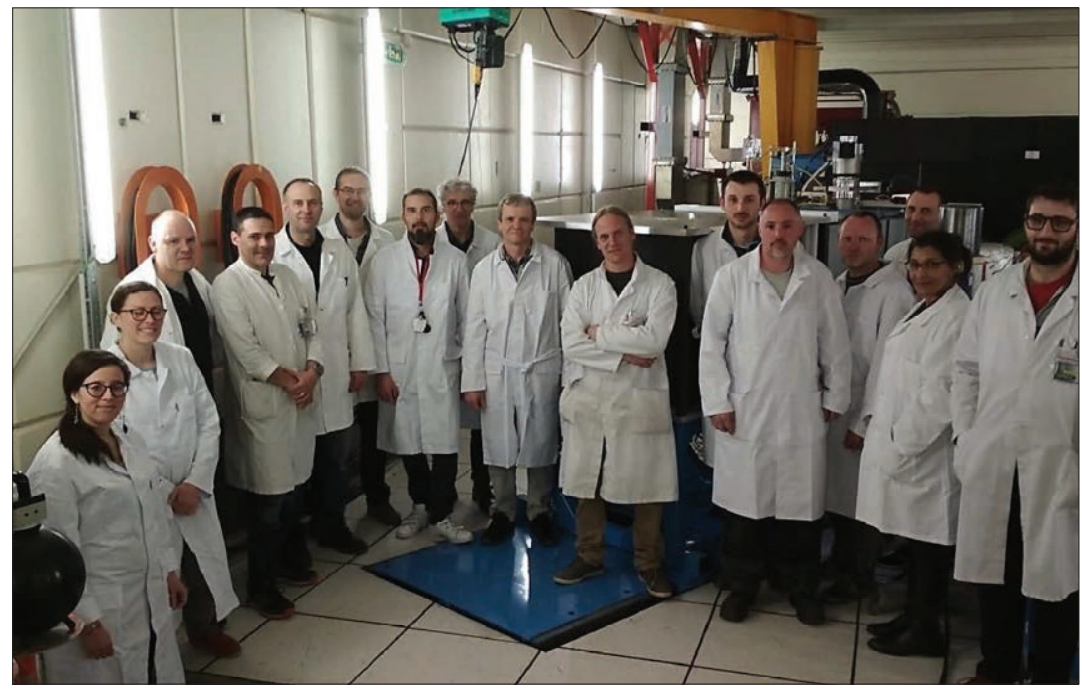

proach that can potentially offer performances on par with medium power research reactors and spallation sources in the field of neutron scattering. Ulrich Rücker and Alain Menelle showed that simulations suggest high-end CANS can be competitive for SANS, Diffraction or TOF Spectroscopy. This was partic- ularly well illustrated by Dr. Xu who presented texture measurements performed at various facilities (RANS@ Riken, J-PARC and a medium-size reactor); similar quality data could be obtained with the RANS facility operated at a power lower than $1 \mathrm{~kW}$. While the collection time was much longer, of course, CANS offer much easier and faster access for industrialists, students and scientists at a fraction of the cost of large-scale facilities.

Hence, it is foreseen that CANS could play a significant role in the future neutron landscape. Japan and China are leading the way by building several CANS facilities which will complement their large-scale facilities (J-PARC, CSNS, CARR). In the case of Europe, given the anticipated closure of several research reactors, CANS projects in France (SONATE), Germany (HBS), Spain, Italy and Hungary should also become a key part of the future European neutron scattering landscape by providing easy access beam time to users to maintain their current high levels of expertise so as to maximize the efficient use of the large-scale facilities such as ESS and ILL.

The conference covered a very wide range of topics around all aspects of compact sources, accelerators, targets, moderators, detectors, neutron scattering, radiography, isotope and nuclear data, and medical applications. The conference website (ucans8.sciencesconf.org) gathers the presentations of most of the 60 speakers at the conference. Conference proceedings will be published in EPJ Web of Conferences and should be available in early 2020 .

The next UCANS meeting will take place in Japan in 2020.

\section{ORCID}

\section{Frédéric Ott (iD}

http://orcid.org/0000-0003-1562-4644

\author{
C. Alba-Simionesco, \\ A. Menelle, and F. Ott \\ Laboratoire Léon Brillouin \\ CEA/CNRS, Univ. Paris Saclay
}

AQ1 